\title{
Pepe Mujica: \\ deconstruyendo el discurso que cautivó al mundo
}

\section{Katherine Pose* \\ Oscar Mañán**}

Resumen. Una vida austera, una forma peculiar de hablar, su biografía y ascenso hasta la presidencia de la República de Uruguay, le otorgaron una gran popularidad a escala mundial a Pepe Mujica, un personaje que es revisado mediante el análisis de su discurso, en particular cinco piezas pronunciadas en foros mundiales y nacionales, que develan signos ideológicos: la utopía del Sur, la civilización del despilfarro, la idea de felicidad, la noción de los pobres del mundo y la categoría de pueblo. El uso de frases populares, expresiones de sentido común y su socorrido lema: «como te digo una cosa, te digo la otra», dan cuenta de un discurso político que penetra la subjetividad popular y galvaniza los medios de comunicación. No obstante, conviene ir más allá del discurso, para contratar lo dicho con lo hecho, para entender al personaje de arrastre popular y a los políticos de la nueva ola latinoamericana que postulan proyectos nacionalistas, populistas o progresistas.

Palabras clave: Pepe Mujica, discurso, ideología, política, Uruguay.

* Estudiante del Profesorado de Sociología en el Centro Regional de Profesores del CentroCFE-ANEP, Florida, Uruguay.

" Profesor del Departamento de Sociología del Centro Regional de Profesores del CentroCFE-ANEP, Florida, Uruguay.

Este trabajo es parte de un análisis más amplio presentado por Katherine Pose para la evaluación de un curso de Política, Estado y Ciudadanía del 3er. año de la Carrera de Formación Docente para el Profesorado de Sociología del Centro Regional de Profesores del Centro, Florida Uruguay. 


\section{Pepe Mujica: \\ deconstructing the discourse that captivated the world}

Abstract. A frugal life, a unique manner of speech, an unusual background and ascent to the presidency of the Republic of Uruguay, brought enormous global popularity to Pepe Mújica, the figure who is the under study here through an analysis of his discourse, in particular five examples of his lectures in global and national fora, which reveal certain ideological traits: the Southern utopia, the throwaway society, the concept of happiness, the notion of the poor of the world and the concept of community. His use of colloquialisms, common-sense expressions, and his frequent slogan: «como te digo una cosa, te digo la otra» («on the other hand...»), reveals a political discourse that seeps into the public consciousness and captivates the mass media. However, it is worth diving deeper into this discourse, to contrast what is said with what is done, to understand a persona that is popular with the masses and the Latin American new wave politicians who support nationalist, populist or progressive projects.

Keywords: Pepe Mujica, discourse, ideology, politician, Uruguay. 
La relevancia de la figura de Mujica, tanto en Uruguay como en el mundo, hace interesante el esfuerzo de deconstruir en el sentido de Jacques Derrida (1989) o Martin Heidegger (1951) su base discursiva a partir del análisis de su estructura en cinco intervenciones llevadas a cabo en diferentes ocasiones que impactaron a sus auditorios. La simpleza de su léxico parece escapada de las páginas de Jerzy Kosinski ${ }^{1}$ o quizás se asemeja a la charlatanería de André Malraux. ${ }^{2}$ A veces, deja entrever que encierra más riqueza que la que de por sí tienen sus máximas, y otras, se camufla en complejidades que no se terminan de entender completamente. La utilización de dichos populares, frases del sentido común y su popularizada «como te digo una cosa te digo la otra», marcaron un discurso político propio, particularmente desafiante de la razón, y por lo tanto, difícil de confrontar con las herramientas de la lógica científica.

${ }^{1}$ El célebre trabajo del escritor polaco-estadounidense, archi-premiado en varios países y que marcara toda una generación (Being There, Harcourt Brace Jovanovich, 1971, versión original en inglés, intitulada Desde el Jardín en Latinoamérica y Bienvenido Mr. Chance en España) dio lugar a una comedia igualmente reconocida, dirigida por Hal Ashby y protagonizada por Peter Sellers. La película (1979) no hace del todo justicia a la novela si bien cosechó múltiples premios y elogios, ya que su trama lleva a la comedia a un jardinero (ermitaño, de escaso roce social y que sabe del mundo por la televisión) que al enfrentarse al mundo real solo habla de las plantas que es el saber propio de su experiencia de vida, pero seduce, prensa y relaciones mediante, a las finanzas y la política que lo interpretan no en el sentido literal que él expone sino con sentidos mentados a lo que esperan escuchar.

${ }^{2}$ Su más brillante y controversial trabajo La Condition Humaine, Éditions Gallimard, Paris, 1946 en su versión original en francés, o La condición Humana, Pocket-Edhasa, Barcelona, 1999, según traducción española (de César Comet), donde se mezcla una historia épica, el romanticismo, la inteligencia, imaginación desmedida, ideologías y articulaciones culturales múltiples. 


\section{El personaje...}

José Alberto Mujica Cordano, «alias Pepe» se convirtió en figura popular en el continente y el mundo, ex guerrillero (integrante del Movimiento de Liberación Nacional), preso político y rehén de la dictadura militar, se reincorporó a la vida política institucional, convirtiéndose primero en diputado, luego senador y por último presidente de la República en Uruguay.

Su carta de presentación en el mundo, su vida austera, en una pequeña parcela alejada de la ciudad, que trabaja aún (al estilo campesino o pequeño farmer americano), por su vestimenta humilde y su forma de hablar campechana, su polémica forma de enfrentar a la prensa, sus dichos sobre la política entre otras actitudes poco comunes en el establishment político.

A nivel internacional su fama cruzó fronteras y océanos, se le profesa gran admiración, especialmente por su modus vivendi lejos de la visión tradicional de los políticos a pesar del poder que ejercen en distintos ámbitos; como también es justo decirlo, enfrenta a nivel nacional fuertes críticas, ya sea a lo que fue a su gobierno, al personaje que encarna y a sus polémicos decires.

\section{El guion para el análisis de contenido}

Analizar un discurso implica una estrategia de deconstruir o desmontar su estructura lógica, es decir, tomar debida cuenta de aquellas partes o conceptos que le dan forma al lenguaje, a la vez que las circunstancias históricas en que cobra sentido. Este ejercicio permite separar y enjuiciar aquellos conceptos o expresiones ambiguas de otras más potentes, de las que cumplen una función retórica de otras que son parte esencial del mismo. 
Se analizarán las siguientes intervenciones: un discurso a los intelectuales de Uruguay (2009); otro en ocasión de la asunción del mando presidencial (2010); su intervención en la cumbre de la Asamblea de la ONU en Río de Janeiro (2012); el particularmente conocido en la Asamblea General de las Naciones Unidas en Estados Unidos (2013); y por último, el discurso de despedida de su gobierno (2015). Este ejercicio se vuelve indispensable para intentar comprender los motivos por los que su oratoria alcanzó popularidad, tanto por los visos inusuales de su discurso, aparentemente simple y a su vez atrapante; con una exaltación del valor de lo común que impresiona el sentir popular y la suficiente charlatanería que atrapa la cultura libresca.

A partir de las temáticas en cada uno de los discursos, se analizan cinco signos ideológicos para tratar de descifrar los ideologemas, al decir de Bajtin, presentes en los decires de José Mujica. Para esto se toman signos ideológicos que se reiteran en todos estos discursos: a) lo que es posible nombrar como «la utopía del sur»; b) siguiendo por «la civilización del despilfarro»; c) y relacionándolo con «la idea de la felicidad», d) el ideal de «los pobres del mundo» y, e) finalmente la construcción política de la categoría «pueblo». A través de estos signos ideológicos se pretende comprender los ideologemas recurrentes en los discursos de Mujica.

Se utiliza la idea de signo ideológico tanto en calidad de palabra «cargada» como de sintagma «cargado», ya que la signidad no está en una sola palabra sino en un sintagma; por ejemplo: en «la civilización del despilfarro». Todo discurso está preñado de la ideología del autor, el cual se marca a través de los signos ideológicos que utiliza: «Todo producto ideológico (ideologema) es parte de la realidad social y material que rodea al hombre, es momento de su horizonte ideológico materializado» (Bajtin y Medvedev, 1994:48). 
Se concibe al discurso como un término con variadas acepciones, por lo que se utiliza una definición amplia y general aportada por Concepción Otaola (1989) como el uso del lenguaje, la lengua en funcionamiento, el cual puede ser oral o escrito, tiene un fin comunicativo y es también un proceso.

Tales signos ideológicos cobran sentido a partir del contexto en el cual se circunscriben, por lo que es de gran relevancia tomar en cuenta la situación, el texto en el contexto, como medio para descubrir la función que cumple el discurso. El tema de un enunciado no está determinado solo por las formas lingüísticas que lo contienen (palabras, estructuras morfológicas y sintéticas, sonidos y entonación) sino también por factores extra-verbales de la situación (Voloshinov, 1976). Para comprender un discurso se debe tener en cuenta el contexto en el cual se pronuncia. El contexto se comprende como un concepto sociocultural, para analizar la manera en que las personas que forman parte de un grupo o subgrupo le asignan significado a los parámetros físicos de una situación y a lo que allí sucede en un momento dado (Calsamiglia y Tusón, 2002).

Es relevante la consideración de este fenómeno a la hora de comprender los discursos, particularmente los pronunciados en asambleas internacionales, porque éstos se distancian relativamente del léxico propio de Mujica en entrevistas, comentarios de prensa y otro tipo de charlas. Los discursos tomados aquí tienen una estructuración lógica y articulación temática un tanto diferente a la oratoria en otros ámbitos menos formales, si bien pueden identificarse palabras típicas de su léxico, éstas no están tan cargadas de cliches y dichos populares. Aquí se entiende por formalidad el ámbito que implica además del discurso oral, cierta articulación con el texto como guía, lo que implica un grado de elaboración previa. 


\section{La utopía del sur}

Mujica en la Asamblea General de las Naciones Unidas en Estados Unidos 2013, comienza destacando las cualidades de Uruguay: «Amigos todos, soy del sur, vengo del sur. Esquina del Atlántico y del Plata, mi país es una penillanura suave, templada, una historia de puertos, cueros, tasajo, lanas y carne» (Mujica, 24 de septiembre de 2013). A través de este primer enunciado se destaca la idea del sur. Este signo ideológico será parte fundamental en su estructuración discursiva y se repetirá en otros. Detrás de la simpleza de una presunta ubicación geográfica, se trama una red de significados que aluden a cierta representación, el sur como periferia, pobre, carenciado, en contraste con el norte desarrollado.

El signo ideológico del sur marca un discurso histórico del país, canónico, impregnado en el sentido común del uruguayo, el que se enseña desde la educación primaria. La descripción del paisaje, como penillanura, con el clima templado y a través de lo que era su principal actividad: la ganadería extensiva. Mujica a través de las características que presenta define a Uruguay y también lo diferencia del resto del continente, esta visión de país pequeño, de excepción, sin grandes riquezas, igualmente pudo ser un país libre y emancipado, alejándose de la dominación imperialista (Real, 1964).

Mujica menciona el proyecto fundacional Batllista (por José Batlle y Ordóñez, presidente en 1903-1907 y 1911-1915), donde el país «se puso a ser vanguardia en lo social, en el Estado, en la enseñanza». Podría pensarse que la función manifiesta de estos enunciados es la descripción histórica de un país; pero quizás hilando más fino, aparece una función latente que denota ciertas ganas de ubicar al país en una posición de relevancia con 
respecto a los países centrales, reivindicando la importancia del sur. Esto se reafirma en el discurso pronunciado en la cumbre de Río de Janeiro: «En mi país hay poco más de 3 millones de habitantes. Pero hay unos 13 millones de vacas, de las mejores del mundo. Y unos 8 o 10 millones de estupendas ovejas. Mi país es exportador de comida, de lácteos, de carne. Es una penillanura y casi el 90 por ciento de su territorio es aprovechable» (Mujica, 20 de junio de 2012).

Se sigue realzando la imagen de Uruguay como país productor, pero, en definitiva, país productor de bienes primarios, característica propia de los países de la periferia tal como lo argumentaba la Cepal (Rodríguez, 2006).

Podría pensarse que es un discurso contrahegemónico, al decir que «la socialdemocracia se inventó en el Uruguay» se realza la producción propia del ideario del país. Si bien menciona al sur como continente, destaca más que nada la importancia de Uruguay, diferenciándolo a su vez del resto de los países latinoamericanos.

En contrapartida, a esta idea se le suma lo que también podría considerarse otro signo ideológico, la idea de patria común estrechamente vinculada con el sur y sus libertadores (Bolivar, San Martín, Artigas). Y dice Mujica en su discurso de la ONU: «Pero soy del sur y vengo del sur a esta asamblea, cargo inequívocamente con los millones de compatriotas pobres, en las ciudades, en los páramos, en las selvas, en las pampas, en los socavones, de la América Latina patria común que se está haciendo» (Mujica, 24 de septiembre de 2013).

Reitera su procedencia del sur, pero le suma una carga que, a su vez dice no pertenecerle, de los millones de pobres que en el continente habitan. Quizás cabría preguntarse por qué lo siente como una carga, si a su 
vez dice que es inequívoca. Por último, menciona a América Latina como una patria común en construcción, es aquí donde aparecen señales de un discurso un tanto artiguista o bilivariano, donde a diferencia de la «federación» que pretendía Artigas, o de la «patria grande» de la que hablaba Bolívar, Mujica alude a una patria común, ¿será una forma de «regionalismo abierto»? ${ }^{3}$ Como lo pensaba Simón Bolívar en 1814 cuando les habría dicho a los soldados de Urdaneta: «Para nosotros la Patria es América». En su conocida Carta de Jamaica, expresa «es una idea grandiosa pretender formar de todo el Nuevo Mundo una sola Nación con un solo vínculo que ligue sus partes entre sí y con el todo» (Bolivar, 1991:16).

Al igual que ciertos discursos de Bolívar, el discurso de Mujica tiene cierto personalismo, entendiendo a éste como un discurso político que se centra más en la construcción identitaria del orador que en una construcción de corte colectivo (Molero, 2002). Es por esto que se visualiza como «cargando» a los pobres (figuradamente en sus espaldas), que habla de su propio estilo de vida austero, «en mi humilde manera de pensar» que se posiciona como un «viejo reumático al que se le fue la vida», describiéndose como un anciano, pero con cierto grado de sabiduría.

Podría decirse que Mujica toma este discurso antiimperialista, pero en una nueva era, que como expresa, está regida por la globalización. Es aquí donde se encuentra una de las tantas ambivalencias en su discurso, trata de buscar un mundo sin fronteras, pero a su vez menciona que se debe controlar la globalización. Tendría que comprenderse entonces, las dos formas en las cuales utiliza el término, a veces globalización como interconexión

${ }^{3}$ Concepto surgido a instancia del primer ministro japonés Masayoshi Ohira a fines de los 1970 que para superar diferencias económicas y políticas en la zona asiática proponía una cooperación internacional ampliada. Cepal (1994) lo descubrió en la década de los 1990. 
de los países, otras veces globalización como transnacionalización, donde la economía depende de las grandes empresas que se desarrollan en varios países con independencia de las leyes nacionales (Canclini, 2006).

Esta ambigüedad en un mismo discurso se expresa cuando menciona por un lado «Más claro, creemos que el mundo requiere a gritos reglas globales» y por el otro comenta que «hoy el mundo es incapaz de crear regulación planetaria a la globalización y esto es por el debilitamiento de la alta política, eso que se ocupa de todo» (Mujica, 24 de septiembre de 2013). Es posible preguntarse: ¿Cómo crear reglas mundiales sino es a través de la política? ¿Cómo crear reglas mundiales en un mundo donde los Estados Nación siguen siendo esenciales? ¿Cómo crear reglas mundiales donde la soberanía de cada país sigue medianamente vigente (por lo menos la de los grandes? ¿Será todo esto realmente posible, o simplemente, una prosa bonita que sabe a letra muerta?

En el acto de asunción Mujica expresa «los humanos anudamos nuestro destino y nos hacemos mutuamente dependientes. La idea de cerrase al mundo quedó obsoleta» (Mujica, 1 de marzo de 2010). Una idea de apertura que podría pensarse que concuerda con la patria común de la habló en otros discursos, empero contradice la idea de controlar la globalización. Asimismo, en dicho acto se pronuncia a favor de una economía de mercado global, expresado en la misiva «Sería criminal no aprender de aquellos dolores y volver a una economía enjaulada y cerrada al mundo» (Mujica, 1 de marzo de 2010, el énfasis es de los autores).

Aprender del pasado, para el ex presidente, encierra la idea de evaluar como fracaso el proteccionismo tanto Uruguay como de la región en épocas del llamado desarrollo de los mercados internos. Cuestión difícil de justificar si remitimos a datos empíricos de crecimiento, desarrollo sectorial 
e infraestructura, institucionalidad para la planificación de políticas, etc. Ciertamente, alude de una forma menos explícita a otros ejemplos del continente que han sufrido bloqueos, y por lo tanto, aislamiento. Con esto busca el fundamento para una economía abierta, cuestión que si lo afirmara de manera textual, provocaría un mayor impacto, particularmente por su connotación ideológica en la izquierda que él mismo dice representar. De allí, que el rechazo a una «economía cerrada» no enfrenta abiertamente a quienes lo identifican con los valores de la izquierda y se granjea al establishment liberal.

Fue en la cumbre de Naciones Unidas donde había rechazado totalmente esta idea de sociedad de mercado, expresando que ésta es la que «está agrediendo al planeta». Es en este punto donde el contexto se vuelve un elemento fundamental para comprender el sentido que se le da al fenómeno de la globalización. En Río de Janeiro, la reunión se destinó al tratamiento del crecimiento económico y el desarrollo sostenible, dedicando gran espacio a la crisis ambiental. Por lo tanto, fue aquí que el discurso de Mujica se basó más en una crítica a los procesos de globalización económica como generadora de la crisis ecológica que a evaluar los supuestos beneficios de una economía abierta para un país como Uruguay.

En definitiva, estos discursos remiten a un ideologema que se basa en el deber ser, en una oratoria que tiene la finalidad de impactar a través de ideas, signos ideológicos que aludan a lo que se debería estar haciendo, sin plantearse ese Ser propiamente (lo que efectivamente se hace), las causas de todos los males que nombra. 


\section{Civilización del despilfarro}

El tema de la globalización es reiterado en los discursos de Mujica tanto como complejo de entender. Menciona en la Cumbre de Río que «el hombre no gobierna las fuerzas que ha desatado», aludiendo al impacto ambiental que la globalización genera. A su vez, el referirse a una fuerza ingobernable oculta un sentido de negación a nuevas formas de sociedad, si bien su discurso expresa que no se puede ni se debe retroceder, tampoco apunta a un futuro diferente y posible.

Es así que otro nuevo signo ideológico que se reitera en todos los discursos analizados de Mujica, es la civilización del consumo del «úselo y tírelo» como la define, la civilización hija del mercado, la que provoca los males de la naturaleza. En la forma en la que lo expresa ante la ONU, contrapone la sociedad actual con el ambiente natural: «La crisis ecológica del planeta, es consecuencia del triunfo avasallante de la ambición humana» (Mujica, 24 de septiembre de 2013). Mediante los términos «triunfo avasallante» se apunta a una sociedad industrial, pero también a cierta cultura del consumo que como lo expresa «la cultura consumista que nos rodea a todos, las repúblicas frecuentemente en sus direcciones adoptan un diario vivir que excluye, que pone distancia con el hombre de la calle» (Mujica, 24 de septiembre de 2013).

Desde esta perspectiva, la exclusión se cataloga como aquellos que no llegan a ser parte de esa cultura del consumo, pero que asimismo es producto de dicha cultura. Queda clara la complejidad que sus palabras encierran, donde se cuestiona, pero no se propone nuevas formas de enfrentar este problema, exalta una mera crítica ya instalada en la conciencia de muchas personas. Cabe destacar también que esta temática no es nada 
innovadora, la práctica discursiva contemporánea se caracteriza por el tratamiento frecuente de ciertos temas, entre ellos: el consumo (Fairclough, 2008).

Estrechamente vinculado con esta civilización del consumo, queda el ideologema del desarrollo sustentable que se expone en distintos discursos de Mujica. Ideologema, porque el tratamiento de la crisis ambiental también esconde cierta ideología. Y, en la cumbre de Río, Mujica dice: «Tenemos que darnos cuenta que la crisis del agua y de la agresión al medio ambiente no es la causa. La causa es el modelo de civilización que hemos montado. Y lo que tenemos que revisar es nuestra forma de vivir» (Mujica, 20 de junio de 2012).

Podría pensarse en un primer momento que la crítica hacia el modelo de civilización que «hemos montado» donde él se incluye, es un discurso que ataca al modelo civilizatorio capitalista hegemónico. Pero no es así. Se relaciona esta postura con la posición adoptada por los organismos internacionales que se ubican como ambientalistas (no ecologistas). Su característica es no tener una visión holística de la vida, es decir, realizan una crítica superficial a la sociedad pero sin proponer cambios en el modelo de producción y de consumo; por lo que no existe un compromiso real con un cambio social que pudiera provocar un declive en el ritmo de acumulación capitalista (Velázquez, 2014). Al igual que el expresidente, se cuestiona el modelo de sociedad actual, realizando un llamado a la acción, a cambiar el estilo personal de vida de cada uno; pero no propone cambios que impliquen la intervención de los gobiernos, los movimientos sociales, la gran política, como forma de revertir el problema ambiental.

En el discurso de asunción de la Primera Magistratura del país el medio ambiente se encontró dentro de los cuatro asuntos tratados por Mujica. 
Expone: «Hoy la comunidad internacional nos pide que nos pensemos a nosotros mismos como miembros de una especie cuyo hábitat está cada vez más amenazado» (Mujica, 1 de marzo de 2010).

En primer lugar, la utilización de la palabra «especie» marca un claro distanciamiento con la palabra «civilización» ya que esta última quedaba vinculada con esa sociedad industrial, consumista. Al tratarse de especie, unifica a la población, pero con una connotación más biológica que cultural.

En segundo lugar, adopta la posición de los organismos internacionales, estos que muchas veces recargan la responsabilidad del deterioro ambiental en los países periféricos. Una característica de los discursos políticos, y de la que no escapa Mujica, es el hecho de referirse al presente percibido como tendencia negativo, y al futuro, con referencias positivas (Van Dijk y Mendizábal, 1993).

\section{La búsqueda de la felicidad}

Al tratamiento del medio ambiente le agrega una carga emotiva, sentimental, con lo que Mujica concluye su discurso en Río de Janeiro:

El desarrollo no puede ser en contra de la felicidad. Tiene que ser a favor de la felicidad humana; del amor arriba de la Tierra, de las relaciones humanas, del cuidado a los hijos, de tener amigos, de tener lo elemental. Cuando luchamos por el medio ambiente, tenemos que recordar que el primer elemento del medio ambiente se llama felicidad humana (Mujica, 20 de junio de 2012). 
En la actualidad hay una creciente preocupación por la temática de la felicidad, y esta se constituye como el eje de muchos discursos. Mujica expresa la idea de que la felicidad es lo central en la vida humana, y más adelante dice que «venimos al planeta a ser felices» por lo que este debe ser el destino del individuo. A su vez, asume que la felicidad debe de buscarse por fuera del consumismo, tendría que encontrarse en el saber. En el discurso pronunciado hacia los intelectuales, les comenta:

¿Se acuerdan de Rico Mac Pato, aquel tío millonario del pato Donald que nadaba en una piscina llena de billetes? El tipo había desarrollado una sensualidad física por el dinero. Me gusta pensarme como alguien que le gusta darse baños en piscinas llenas de inteligencia ajena, de cultura ajena, de sabiduría ajena (Mujica, 29 de abril de 2009).

La comparación con Mac Pato alude a una diferenciación entre dos tipos de riqueza: la económica y la intelectual. Aquí podría pensarse que hay una separación con la concepción de felicidad de la época actual, donde ésta se consigue a través de la seguridad material lo que marca el signo del éxito social; esta idea de felicidad está estrechamente ligada con el bienestar, así como con el consumo. A través de lo que Mujica desarrolla, la felicidad se fundamenta en la sabiduría, en el intelecto. Podría especularse que su concepto de felicidad remite a la filosofía antigua, donde para ser feliz el conocimiento del universo es esencial, la felicidad no puede ser alcanzada sino a través del conocimiento de lo que es verdadero; lo que se consigue mediante las facultades intelectuales (Margot, 2007). En este punto, Mujica expone la idea de felicidad desde su perspectiva, siguiendo la línea del discurso personalista donde él se pone como ejemplo.

Por otro lado, la selección de este personaje no solo cumple con la finalidad de ejemplificar, sino que además se reserva la utilización de casos 
reales. En alguna entrevista supo hablar de Rockerfeller como una persona ya anciana que sigue amontonando dinero y se cuestiona con qué finalidad; pero al utilizar un personaje animado le quita fuerza a la crítica. Esto es propio por la situación donde se encuentra, en el Palacio Legislativo, con estudiantes universitarios de variadas carreras, por lo que seguramente valoró no generar polémica con los ejemplos.

El ideal de felicidad que esboza esconde un ideologema que remite a una época dada. Desde la década de los 90 se ha instalado en el discurso la idea de la felicidad, en sus diversas variantes, tanto como realización propia, como felicidad a través del consumo. Esto coincide con ciertos objetivos de la racionalidad política neoliberal: mercantilización, individualización, competitividad, entre otros. Así como Mujica apunta a una definición universal de lo que para él es la felicidad, y aparentemente critica a la felicidad que depende del consumo, no escapa que toma a la felicidad como algo objetivo y que legitima esas medidas neoliberales. Al hablar de felicidad, el discurso queda dirigido a la individualidad pretendiendo impactarla, sin una aparente generalización. El discurso neoliberal está caracterizado por expresar que «lo que realmente importa, no es que esa cifra poblacional, abstracta y anónima mejore, sino que tú, que no te sientes representado por las frías estadísticas, seas feliz» (De la Fabián y Stecher, 2013:35).

Desde las concepciones modernas, se apunta a buscar ciudadanos felices, donde estos rindan mejor cognitivamente, se enfermen menos y vivan más. Desde esta perspectiva, la importancia discursiva que se le otorga a la búsqueda de la felicidad queda fundada en una nueva modalidad del «capital humano», donde el costo de producirla es una inversión a futuro (De la Fabián y Stecher, 2013:37). 
Conjuntamente con su idea de felicidad, aquella que corresponde al intelecto, introduce otra correspondiente a la necesidad de una inteligencia distribuida. En su ponencia hacia los intelectuales dice: «La inteligencia que le rinde a un país es la inteligencia distribuida. Es la que no está sólo guardada en los laboratorios o las universidades, sino la que anda por la calle» (Mujica, 29 de abril de 2009). Con el concepto de distribución, connota una forma de compartir los conocimientos, a diferencia de lo que podría transmitir la palabra democratización, aludiendo a un acceso para todos.

En relación a esto menciona un aspecto importante a destacar: «Y ahora agrando el pedido y les ruego que contagien inconformismo». El inconformismo como forma de cuestionarse constantemente, llevaría a pensar que es incongruente con los deseos de todo político. Pero en el discurso de asunción se visualiza como Mujica se va a servir de esta idea: «Bienvenidos al inconformismo (...) bienvenido el profundo cuestionamiento del estado uruguayo» (Mujica, 1 de marzo de 2010). Se sirve de esta idea como mecanismo para insertar el cuestionamiento del Estado y plantear una reforma del mismo.

\section{Los pobres del mundo}

Conjuntamente con este ideario, transmite una particular idea sobre la pobreza. Para Mujica, la pobreza se basa en el nivel de consumo. Como ya se comentó, quienes no se integran a la cultura del consumo quedan excluidos. A su vez, en el discurso pronunciado en la cumbre en Río interroga: «¿Tiene el mundo hoy los elementos materiales como para hacer 
posible que 7 mil u 8 mil millones de personas puedan tener el mismo grado de consumo y de despilfarro que tienen las más opulentas sociedades occidentales?» (Mujica, 20 de junio de 2012).

Desde la perspectiva de Mujica, la pobreza se relaciona con la escasez de consumo, por lo que se cuestiona si es posible que todas las personas adquieran un mismo nivel en el grado de consumo. Desde el modelo del desarrollo sostenible se realiza esta misma crítica, la erradicación de la pobreza requiere de modificaciones en la pauta de producción y de consumo, lo cual es fundamental para este tipo de desarrollo (Martínez, Ortega, Infante y Puente, 2014). De igual forma, Mujica con la interrogante que plantea, invisibiliza un fenómeno no menor, la desigual distribución de la riqueza. Para este líder mundial, las personas no logran un mismo nivel de consumo no porque haya una distribución desigual de la riqueza, donde pocos concentran mucho, sino que por el contrario, porque el mundo no tiene los elementos materiales para que todos estén a un mismo nivel.

Curiosamente, se visualiza una especie de mimesis entre el ideario de Mujica y el sostenido por los organismos internacionales. Es justamente en su discurso en la Asamblea de la ONU, donde dice: «Es posible arrancar de cuajo toda la indigencia del planeta (...) Movilizar las grandes economías, no para crear descartables, con obsolescencia calculada, sino bienes útiles, sin fidelidad, para ayudar a levantar a los pobres del mundo. Bienes útiles contra la pobreza mundial» (Mujica, 24 de septiembre de 2013).

La mención de arrancar de cuajo toda la indigencia corresponde con el ideario discursivo de la ONU el cual como ya se mencionó plantea una posible erradicación de la pobreza (Metas del Milenio). Para Mujica la creación de bienes duraderos ayudaría a «levantar» a los pobres, relacionando a su vez, esta medida como una ayuda al medioambiente. Resulta 
importante destacar que no se menciona en ningún momento los orígenes o causas de la pobreza. Si bien el pensamiento de la ONU busca aminorar la pobreza a partir de principios como igualdad, inclusión y justicia distributiva, genera cierto escepticismo sobre el alcance que podría obtener sus medidas. Este escepticismo se sustenta, en que el organismo no revisa exhaustivamente las causas de la pobreza, los cambios no serían propicios para los sectores más desfavorecidos de la sociedad (Martínez, Ortega, Infante y Puente, 2014).

Con el planteo de que los 7 u 8 mil millones de personas no podrían integrarse a un mismo nivel de consumo, trae reminiscencias de lo que algunos organismos internacionales sostenían en los años 80 y que llevó a las castraciones masivas de niñas y el acelerado envejecimiento en países pobres. En aquel entonces, se discutían las disyuntivas si «éramos pobres porque éramos muchos», o tal vez, «éramos muchos porque éramos pobres». La pobreza existe porque hay muchos individuos en el mundo sostiene de alguna manera el expresidente. Se habla de consumo, pero no de derechos humanos vulnerados, se mencionan formas de aliviar la pobreza en lugar de medidas redistributivas que la cuestionen en su profundidad, se ataca la pobreza para no atacar la riqueza, estos signos ideológicos encierran un ideologema que concibe la pobreza como un fenómeno instantáneo, natural, sin orígenes ni causantes susceptibles de debatirse.

A esta idea le suma la frase «pobre no es el que tiene poco sino el que necesita infinitamente mucho, y desea más y más» siguiendo la idea de la pobreza mental, aquel que necesita infinitamente mucho como quien está integrado y alienado a la cultura del consumo. Pero cabría preguntarse, si de acuerdo a esta definición hay alguien que no sea pobre en el mundo actual. 


\section{La categoría política de «el pueblo»}

La construcción política de esta categoría de pueblo aparece en su discurso en el acto político en que deja el mando del gobierno. Esta categoría es utilizada a menudo por los discursos que se tipifican de populista, donde es recurrente la mención al pueblo con la intención de provocar una reacción emocional en el público (Guy, 2003). «Querido pueblo, gracias por tus abrazos. Gracias por tus críticas, gracias por tu cariño y, sobre todo, gracias por tu hondo compañerismo cada una de las veces que me sentí sólo en el medio de la Presidencia» (Mujica, 1 de marzo de 2015).

Se dirige en agradecimiento al pueblo, con una connotación afectiva, tratándolo a su vez de compañero que estuvo junto a él en tiempos de soledad. Este corte populista suele ser característico de ciertos líderes carismáticos, llevando a la escena política la relación afectiva entre éstos personajes y las masas, dirigiéndose a ellas como «el pueblo» (Malamud, 2010:434). La palabra pueblo está dirigida a ocultar las diferencias a través de una connotación que engloba a un conjunto de sectores bajo el mote de popular, su agradecimiento al decir «querido pueblo» queda estrechamente vinculado con este sector específico.

Más allá de las complejidades que implicaría considerar a Mujica como un personaje político perteneciente al populismo, su discurso coincide con aquellas figuras que, al decir de Weber, buscan interpelar el corazón de las masas basados en el carisma. Mujica es reconocido por la cualidad de su personalidad y considerado un líder o caudillo. El valor del carisma se sustenta en el reconocimiento de las personas, por el gran impacto de sus discursos dentro y fuera del país, incluso mucho más allá del espectro político al que pertenece. 
Los líderes carismáticos poseen una comunicación de carácter emotivo y está claro que Mujica apela a cierta emotividad en sus discursos. Su rechazo a las riquezas es de gran relevancia a la hora de analizar su reconocimiento; este no pasa por su posición socioeconómica, sino por el contrario, por su austeridad y su aparente rechazo a las grandes riquezas. Tal como expresa Weber todo líder carismático desdeña y rechaza la estimación económica, aunque ciertamente ocurre más como pretensión que como hecho (Weber, 1993).

Es posible visualizar una clara diferencia entre el discurso de despedida y el discurso de asunción. En este último, no se agradece al pueblo, esta palabra no aparece en su oratoria. En cambio, dice: «Por mi parte, desearía que el título de «electo» no desapareciera de mi vida de un día para otro. Tiene la virtud de recordarme a cada rato que soy presidente sólo por la voluntad de los electores». Siente, sin duda la elección, como una distinción, ¿quizás piensa que merecida?

¿Habrá aquí una visión comparable a aquella proveniente del movimiento zapatista «mandar obedeciendo»? ¿Será que la palabra «electo» expresada por Mujica refiere al poder delegacional donde fundamentará el ejercicio del poder que le fue otorgado por la comunidad de «electores»? (Dussel, 2006:22). Esto implica que quien gobierne lo haga en función de las demandas de los ciudadanos, Mujica a través del uso de dicho término busca legitimar el ejercicio del poder otorgado. A su vez, la palabra «electores» cambia el significado de su discurso, deja de lado la connotación que se transmitía la palabra pueblo, y toma cierta distancia del público al cual se dirige, con la palabra electores puede acaparar a una población más amplia y no solo a las capas populares, nuevamente aquí el contexto juega un papel fundamental. La variable tiempo discrimina ambos discursos, 
cuando Mujica asume la presidencia todavía no tiene una relación estrecha con su pueblo, y menos aún, la perspectiva de confianza que esboza al final. Sin duda, la confianza no se basaría en los logros de su gobierno (siempre criticado), pero sí en el reconocimiento internacional a su postura de líder carismático.

\section{Del dicho al hecho, un trecho insalvable}

Es interesante para completar un análisis del discurso político, realizar el ejercicio de contrastar, aunque sea a grandes rasgos, lo que se dijo con lo que se hizo realmente. A través de los signos ideológicos que se tomaron en cuenta de los discursos de Mujica, es posible relacionarlos con ciertos aspectos políticos de su gobierno.

En lo que respecta a la patria grande, Mujica en su mandato apostó a una integración regional, a fin de desarrollar una política exterior donde la región participe como bloque fortalecido ante países poderosos. En su gobierno la integración no fue un logro del que pudiera vanagloriarse, el Mercosur estuvo caracterizado por el estancamiento e incluso las relaciones diplomáticas no fueron lo que se esperaba, siendo objeto de fuertes críticas, sobre todo por las restricciones al comercio impuestas por Argentina y el freno a las negociaciones con otros países (Clemente, 2013).

Otro punto a destacar fue su controversial política medioambiental, ya que en la intervención de Río de Janeiro fue el tema estructural de su discurso. Cabe preguntarse si lo que dijo realmente se correspondió con lo que impulsó en su gobierno. Fue Mujica y su gobierno que expresó una gran afinidad hacia la mega-minería, incluso impulsando una ley al respecto. En 
su audición radial llegó a comentar: «Se hinchan las venas del ecologismo porque, en suma, lo que hay es una lucha de intereses. Si no hay actividades mineras y forestales los salarios (en el campo) van a tender a depreciarse» (Mujica, 2014).

Del conflicto que supo generar esta situación, Mujica solo reparó en los planteos de la oposición política, quitándole importancia a las posturas ecologistas que evidenciaban el impacto en el medio ambiente, particularmente la minería a cielo abierto. Sus actos se dejaron llevar por los intereses económicos que esta actividad prometía, más que por la crítica que había realizado al modelo de sociedad actual que funciona en detrimento de la naturaleza.

$\mathrm{Si}$ en discursos como los pronunciados en la ONU se interpelaban el estilo de vida y la sociedad actual, en su gobierno impulsó y legitimó dicha forma de vida gobernada por el mercado. En lo que respecta a la sociedad hija del mercado, fue este modelo el que impulsó desde el gobierno a través de la apertura a la inversión extranjera. Esta apertura fue fundamentada en la generación de riqueza y de trabajo. Faltó sí interrogarse riqueza para quiénes, Mujica abogó por un «capitalismo en serio» pero a partir de «burguesías subsidiadas» (Mañán, 2013).

En un encuentro con empresarios uruguayos y extranjeros Mujica resaltó: «Cuanta más inversión y más crezca la economía, más aumenta la recaudación que necesitamos para fenomenales inversiones sociales» (29 de agosto de 2013). En este caso soportó la idea de que generando riqueza se puede suavizar la pobreza. En la actualidad el análisis de la pobreza no puede hacerse sin considerar la riqueza, la teoría del derrame es a todas luces obsoleta. Al no considerar esto Mujica sigue pensando que, a través del crecimiento económico, se producirá un efecto de filtración (derrame-spillover 
effect) de la riqueza hacia abajo, reduciéndose la pobreza en pos del beneficio generalizado. El exmandatario discursivamente apunta críticas a la sociedad contemporánea, empero sus acciones en el gobierno denotaron un posicionamiento en el paradigma del crecimiento económico donde la lucha contra la pobreza se realiza en un marco armónico, sin exacerbar la conflictividad que implicaría enfrentar la sociedad productora de riqueza/pobreza (Burns, 2007).

En el periodo de gobierno de Mujica se intentó una reforma del Estado para mejorar la eficiencia de la función pública, pero el diagnóstico del expresidente responsabilizaba a los trabajadores de todos los problemas del Estado. Sin embargo, en su acto de asunción, apuntaba que: «Esta reforma, no va a ser en contra de los funcionarios sino con los funcionarios» (Mujica, 1 de marzo de 2015). La Confederación de Organizaciones de Funcionarios del Estado (COFE) afirmó el interés de los trabajadores de participar en una reforma del Estado juzgada imprescindible, pero rechazaron enfáticamente los criterios mercantilistas de una reforma que debilitaba al Estado y la pseudo-participación propuesta a los trabajadores. Los funcionarios públicos sostienen que lejos de los decires de Mujica, el Estado puede llegar a ser lento e irritante pero no es deficiente por culpa de los funcionarios.

Las palabras de Mujica presentan un vaivén importante, oscilan entre los intereses del contexto donde las pronuncia y aparentemente expresan algo que puede llegar a significar lo contrario. En muchos casos, las palabras no se corresponden con los actos. 


\section{Desde el Jardín... la condición humana}

Valga el parangón con la obra «Desde el Jardín», Mujica es también un cultivador de flores, y además, habla fundamentalmente de su vida, lo que lo emparenta con la obra doblemente. La vida del ex presidente fue muy particular, una historia subrealista, pasó de ser guerrillero, preso político de la dictadura militar y rehén de la misma, a convertirse en representante político nacional y Presidente de la República. Asimismo, fue propuesto al Premio Novel de la Paz, figura de muchos libros y películas de distinguidos directores de cine, entre otros logros que desafían cualquier imaginación.

Desde lo expuesto, se pretendió interpretar una muestra de los múltiples discursos y se apeló al análisis de los signos ideológicos utilizados en sus oratorias. Se buscó demostrar que sus discursos se desarrollan en el plano normativo (del deber ser), apelando a cierta moralidad y sentimentalismo. Al igual que Chance (el personaje de la novela) el expresidente construye un discurso con un léxico simple, cargado de ejemplos de su experiencia personal, de su modo de vida, de su austeridad manifiesta. Sin embargo, lo que lo escuchan, líderes mundiales, ciudadanos dentro y fuera de fronteras, le asignan significados $a d$ hoc acorde a sus múltiples necesidades, de allí que tales discursos, incluso desvinculados muchas veces de la lógica formal y de las obligaciones de congruencia, se asumen como «verdades de vida».

En definitiva, el discurso de Mujica se adapta ideológicamente al contexto en el cual se circunscribe, no solo a través del léxico y la forma de expresar sus ideas; sino también a partir de las modificaciones de sus ideologemas. Sus vaivenes políticos, sus ambivalencias discursivas dieron como 
resultado la popularidad de sus discursos, al adaptarse a los intereses de distintos sectores, al cambiar sus ideas de acuerdo a las circunstancias; así logró conseguir adeptos muy diferentes entre sí. Quizá su popularidad puede verse explicada por su frase de cabecera «como te digo una cosa, te digo la otra» que contenta a todos en algún momento.

Su vida misma es un vaivén increíble, representa el clásico «american way life» mejor incluso que la «idílica» sociedad americana, aquel símbolo cultural de que cualquiera puede llegar a ser lo que quiera sin importar el punto de partida. Mujica, atentó contra el sistema capitalista, quiso cambiar el mundo y de manera revolucionaria, pero el mundo terminó cambiándolo. Paradójicamente, le otorgó un papel de guardián de ese mundo que quiso y no pudo cambiar. Es un símbolo en sí mismo del triunfo ideológico y político del capitalismo (por ahora), y por lo tanto, un mensaje vivo para todos aquellos desafiantes del orden vigente. Pese a quien le pese, su imagen remite a un guerrillero arrepentido, que a pura voluntad, inteligencia y esfuerzo, pudo aprender de sus «errores».

\section{Referencias}

Bajtin, Mijail y Pavel Medvedev (1994), El método formal en los estudios literarios. Introducción crítica a una poética sociológica, Madrid, Alianza.

Bolivar, Simón (1991), Para nosotros la patria es América, Caracas, Fundación Biblioteca Ayacucho.

Burns, Alison (2007), Politizando la pobreza: hacia una economía solidaria del cuidado, San Salvador, Progressio/Instituto Católico de Relaciones Internacionales. 
Calsamiglia, Helena y Amparo Tusón (2002), Las cosas del decir. Manual de análisis del discurso, Barcelona, Ariel.

Canclini, Nestor (2006), «La globalización: ¿productora de culturas híbridas?», en Javier Encina y Manuel Montañés (coords.), Construyendo colectivamente la convivencia en la diversidad: los retos de la inmigración, Sevilla, UNILCO.

Clemente, Isabel (julio-diciembre de 2013), «Política exterior de Uruguay en el Mercosur durante el gobierno de José Mujica», Século XXI, 4(2).

Comisión Económica para América Latina (Cepal) (1994), Regionalismo abierto en América Latina y el Caribe. La integración económica al servicio de la transformación productiva con equidad, Santiago de Chile, Cepal.

De la Fabián, Rodrigo y Antonio Stecher (julio-diciembre, 2013), «Nuevos discursos acerca de la felicidad y gubernamentalidad neoliberal: ocúpate de ser feliz y todo lo demás vendrá por añadidura», Sociedad Hoy (25).

Derrida, Jacques (1989), La desconstrucción en las fronteras de la filosofía. La retirada de la metáfora, Barcelona, Paidós.

Dussel, Enrique (2006), 20 tesis de política, México, Siglo XXI.

Fairclough, Norman (2008), «El análisis crítico del discurso y la mercantilización del discurso público: las Universidades», Discurso y sociedad, 2(1), pp. 170-185.

Guy, Hermet (2003), «El populismo como concepto», Revista de Ciencia Politica, XXIII(1).

Heidegger, Martín (1951, trad. José Gaos), El Ser y el Tiempo, México, Fondo de Cultura Económica.

Malamud, Carlos (2010), Historia de América, Montevideo, Alianza.

Mañán, Oscar (2013), «Uruguay y su utopía progresista: una sociedad más justa con burguesías subsidiadas», en Víctor Palacios y José Valenzuela (coords.), 


\section{Katherine Pose | Oscar Mañán}

Crisis neoliberal y alternativas de izquierda, México: Porrúa/Universidad Autónoma Metropolitana.

Margot, Jean-Paul (julio-diciembre de 2007), «La felicidad», Praxis Filosófica (25), pp. 55-79.

Martínez, Elena, María Ortega, José Infante y Julio Puente (septiembre-diciembre, 2014), «El referente de la pobreza en el discurso de la ONU sobre el desarrollo sostenible», Convergencia, 21(66).

Molero de Cabeza, Lourdes (abril-junio de 2002), «El personalismo en el discurso político venezolano. Un enfoque semántico y pragmático», Espacio Abierto, 11(2), pp. 291-334.

Mujica, José (29 de abril de 2009), «Discurso a los intelectuales», Montevideo, Palacio Legislativo, en http://www.beersandpolitics.com/discursos/ jose-pepe-mujica/mac-pato/542

(1 de marzo de 2010), «Discurso de Asunción como Presidente», Montevideo, en http://www.beersandpolitics.com/discursos/jose-pepe-mujica/ asuncion-como-presidente -de-uruguay/86

(20 de junio de 2012), «Discurso en la cumbre de Río+20», Conferencia de Desarrollo Sostenible de Naciones Unidas, Río de Janeiro, en http://www.beersandpolitics.com/discursos/jose-pepe-mujica/discurso -en-la-cumbre-rio-20/1586

(29 de agosto de 2013), «Presidente Mujica defiende la minería para mejorar la vida en Uruguay», América Economía, en https://www.americaeconomia.com/negocios-industrias/presidente-mujica-defiende-la-mineria -para-mejorar-la-vida-en-uruguay

(24 de septiembre de 2013), «Intervención en la $68^{\circ}$ Periodo de Sesiones de la Asamblea General de las Naciones Unidas», Nueva York, en http://www. beersandpolitics.com/discursos/jose-pepe-mujica/discurso-en-la-onu/1410 
(2014), «La minería es una oportunidad para generar inteligencia y conocimiento nacional», Presidencia de la República, Montevideo, en https:// www.presidencia.gub.uy/comunicacion/comunicacionnoticias/mujica -megamineria (1 de marzo de 2015), «Discurso de despedida de gobierno», Montevideo, en http://www.beersandpolitics.com/discursos/jose-pepe-mujica/discurso -de-despedida/1557

Otaola, Concepción (1989), «El análisis del discurso. Introducción teórica», Epos: Revista de Filología (5), pp. 81-98.

Real de Azúa, Carlos (1964), El impulso y su freno, Montevideo, Banda Oriental. Rodríguez, Octavio (2006), El estructuralismo latinoamericano», México, Siglo XXI/Comisión Económica para América Latina.

Van Dijk, Teun y Rodrigo Mendizábal (1999), Análisis del discurso social y politico, Quito, ABYA-YALA.

Velázquez, Manuel (2014), «El discurso hegemónico ambiental a través de organismos de cooperación y su influencia en las relaciones internacionales», Revista Científica General José María Córdova (12), pp. 191-202.

Voloshinov, Valentín (1976), El signo ideológico y la filosofía del lenguaje, Buenos Aires, Nueva Visión.

Weber, Max (1993), Economía y sociedad, Madrid, Fondo de Cultura Económica. 